\title{
Electrocardiogram frequency change by extracorporeal blood perfusion in a swine ventricular fibrillation model
}

\author{
Jung Chan Lee ${ }^{1 *}$, Gil Joon Suh ${ }^{2}$ and Hee Chan Kim ${ }^{1,3}$
}

\footnotetext{
* Correspondence: ljch@snu.ac.kr ${ }^{1}$ Institute of Medical and Biological Engineering, Medical Research Center, Seoul National University, Yongon-dong 28, Jongro-gu, Seoul 110-744, Republic of Korea Full list of author information is available at the end of the article
}

\begin{abstract}
Background: Extracorporeal cardiopulmonary resuscitation (ECPR) refers to the application of extracorporeal blood circulation with oxygenation as a resuscitation tool. The objective of this study is to observe the frequency component changes in the electrocardiogram (ECG) by ECPR during prolonged ventricular fibrillation (VF).

Methods: Six swine were prepared as a VF model. Extracorporeal blood circulation with a pulsatile blood pump and oxygenator was set up for the model. ECG signals were measured for 13 min during VF and analyzed using frequency analysis methods. The median frequency (MF), dominant frequency (DF), and amplitude spectrum area (AMSA) were calculated from a spectrogram obtained using short-time Fourier transform (STFT).

Results: MF decreased from $11 \mathrm{~Hz}$ at the start to $9 \mathrm{~Hz}$ at 2 min after VF and then increased to $11 \mathrm{~Hz}$ at 4.5 min after VF. DF started at $7 \mathrm{~Hz}$ and increased to $11 \mathrm{~Hz}$ within the first min and decreased to $9 \mathrm{~Hz}$ at 2 min, then increased to $12 \mathrm{~Hz}$ at 4.5 min after VF. Both frequency components decreased gradually from 4.5 min until 10 min after VF. After the oxygenated blood perfusion was initiated, both MF and DF increased remarkably and exceeded 12 and $14 \mathrm{~Hz}$, respectively. Similarly, AMSA decreased gradually for the first $10 \mathrm{~min}$, but increased remarkably and varied beyond $13 \mathrm{mV} \cdot \mathrm{Hz}$ after the oxygenated blood supply started. Remarkable frequency increases in ECG due to the oxygenated blood perfusion during ECPR were observed in the swine VF model.
\end{abstract}

Conclusions: The ECG frequency analysis during ECPR can give the resuscitation provider important information about the cardiac perfusion status and the appropriateness of the ECPR setup as well as the prediction of defibrillation success.

Keywords: Electrocardiogram (ECG), Frequency analysis, Extracorporeal cardiopulmonary resuscitation (ECPR), Ventricular fibrillation (VF)

\section{Background}

More than $50 \%$ of cardiac arrests are due to ventricular fibrillation (VF). Early defibrillation is the best treatment for short duration of VF. However, immediate defibrillation for prolonged VF with ischemia results in critical damage to the heart and increase of myocardial blood perfusion should be performed prior to countershock. Chest compression by cardiopulmonary resuscitation (CPR) procedure is an effective way to improve the myocardial blood flow during VF. To determine the suitable intervention for

\section{() Biomed Central}

(C) 2013 Lee et al.; licensee BioMed Central Ltd. This is an open access article distributed under the terms of the Creative Commons Attribution License (http://creativecommons.org/licenses/by/2.0), which permits unrestricted use, distribution, and reproduction in any medium, provided the original work is properly cited. 
a specific time during VF and to predict the defibrillation success, various electrocardiogram (ECG) analysis methods have been studied. ECG during VF delivers much important information describing the fibrillating heart status. Analyzing the ECG during VF can be used to predict the defibrillation outcome [1]. Amplitude [2], frequency $[3,4]$, bispectral analysis [5], amplitude spectrum area (AMSA) [6], wavelets [7,8], and $\mathrm{N}(\alpha)$ histograms [9] obtained from an ECG signal have been used to estimate the duration of VF. Frequency analysis showed a high correlation between cardiac perfusion pressure and the return of spontaneous circulation (ROSC) [10]. Fibrillation frequency and myocardial blood flow are also highly correlated during VF [11]. In particular, several studies reported that an increase in fibrillation frequency during VF occurs due to the chest compressions in the CPR procedure $[12,13]$. These studies imply that a myocardial perfusion condition in fibrillating the heart could be estimated using the ECG frequency analysis.

Extracorporeal cardiopulmonary resuscitation (ECPR) refers to the application of extracorporeal blood circulation with oxygenation as a resuscitation tool. Since the first ECPR concept was proposed as early as the 1960s [14], many researches of ECRP were performed for in-hospital and out-of-hospital settings. Although the current resuscitation guidelines do not consider ECPR as a recommended practice particularly in outof-hospital arrest due to its critical need for expertise [15,16], the improved outcomes of ECPR have been continuously reported for out-of-hospital events and pediatric applications [17-22].

Although ECRP aims to circulate the oxygenated blood through the body, in particular through the arrested heart, the change in the ECG frequency during ECPR has not been studied in detail. We assumed that a strong change of frequency component by an effective blood perfusion to the fibrillating heart would occur similar to the chest compression. We examined a VF animal model while delivering oxygenated blood to a fibrillating heart using a blood pump, and the ECG signals obtained during the VF were investigated using the frequency analysis methods.

\section{Methods}

\section{Animal preparation and measurement}

All experimental protocols involving animals were reviewed and approved by the Institutional Animal Care and Use Committee of the Seoul National University Hospital.

Six swine (body weight, $30 \mathrm{~kg}$ ) were prepared. All animals had free access to food and water for 7 days. While they fasted 8 hours before experiments, they were given free access to water. The animals were anesthetized with an intramuscular injection of ketamine $(6 \mathrm{mg} / \mathrm{kg})$ and xylazine $(1 \mathrm{mg} / \mathrm{kg})$. Pancuronium $(0.2 \mathrm{~mL} / \mathrm{kg})$ was administrated intravenously as a muscle relaxant. After endotracheal intubation, the animals were connected to a ventilator. The tidal volume was set at $15 \mathrm{ml} / \mathrm{kg}$, and the ventilation rate was set at 22 breathes/min initially and adjusted to maintain end-tidal $\mathrm{CO}_{2}$ at $30-35 \mathrm{mmHg}$. Anesthesia was maintained with 1-2 L/min enflurane at a 1:1 ratio of $\mathrm{O}_{2} / \mathrm{N}_{2} \mathrm{O}$. The right carotid artery was cannulated with a 5-Fr central venous catheter for blood pressure measurements and was rinsed with heparin saline. The internal jugular vein was cannulated for placement of a 5-Fr pacing electrode (St. Jude Medical Inc., St. Paul, MN, USA) to induce VF. A heparin dose of $250 \mathrm{IU} / \mathrm{kg}$ was administered for anticoagulation. 
A 17-Fr arterial catheter was inserted into the abdominal aorta through the right femoral artery. A 15-Fr venous catheter was inserted through the right femoral vein, and its end tip was placed in the right atrium. The blood circuit, including the pump and the membrane oxygenator, was primed with heparinized saline. The draw line and return line of the circuit were connected to the venous and arterial catheters, respectively. T-PLS (BHK, Inc., Seoul, Korea) was employed as a blood pump, which was developed for a heart-lung machine and extracorporeal membrane oxygenation machine [23,24]. An Affinity Oxygenator (Medtronic, Inc., Minneapolis, MN, USA) and an Affinity Arterial Filter (Medtronic, Inc.) were used for membrane oxygenation and airbubble filtering, respectively. Blood flow rates through the blood circuit were measured with an ultrasonic flow meter (Transonic System, Inc., Ithaca, NY, USA).

After all catheterizations had been completed, a tongue sensor was placed for monitoring oxygen saturation, and three standard lead II ECG electrodes were attached to the chest wall. Body temperature was monitored with a rectal thermistor.

VF was induced with a 30-60 mA current for $20 \mathrm{sec}$ via the pacing electrode using a custom-made electrical stimulator. The induction of VF was confirmed by both ECG waveform shape and a diastolic blood pressure below $25 \mathrm{mmHg}$. After successfully inducing VF, oxygen delivery was suspended by stopping the ventilator. After 10 minutes of untreated VF, blood perfusion was started to deliver oxygenated blood to the cardiac tissues. Defibrillation was applied 3 min after the blood pump onset. After a successful defibrillation, the ventilator resumed gas delivery. The blood flow rate by the pump was maintained at $2 \mathrm{~L} / \mathrm{min}$. Figure 1 shows the experimental timeline.

Oxygen saturation, ECG (lead II), body temperature, and blood pressure were monitored continuously during the experiment using a patient monitor (Solar $8000 \mathrm{M}, \mathrm{GE}$ Healthcare, Waukesha, WI, USA). ECG signals were transmitted to a PC via an A/D converter (NI USB-6008, National Instrument, Inc., Austin, TX, USA) and saved at a sampling rate of $300 \mathrm{~Hz}$.

\section{Frequency analysis}

For frequency analysis, ECG waveforms were preprocessed using a band-pass filter with a bandwidth of $4-50 \mathrm{~Hz}$ to reduce the low frequency noise $(<2 \mathrm{~Hz})$ by pulsatile flow of the blood pump and the electrical interference of ambient noise $(60 \mathrm{~Hz})$.

Short-time Fourier transform (STFT) is a representative time-frequency analysis. STFT is also called as windowed Fourier transform. Segmenting the raw signal into a certain time intervals by using a window function, the Fourier transform is applied to each segment as the window function is slid along the time axis. As a result, STFT extracts information which indicates how the spectral content varies over the time. STFT of the time domain signal $\mathrm{x}(\mathrm{t})$ is given as:

$$
\operatorname{STFT}(\tau, f)=\int_{-\infty}^{\infty} x(t) g(t-\tau) e^{-j 2 \pi f t} d t
$$

where $g(t-\tau)$ is a sliding window function. While too wide window results in good frequency resolution and poor time resolution, too narrow window results in good time resolution and poor frequency resolution. In this study, the Hanning window was used as the window function, and its size was approximately $1.7 \mathrm{sec}$ and contained 512 


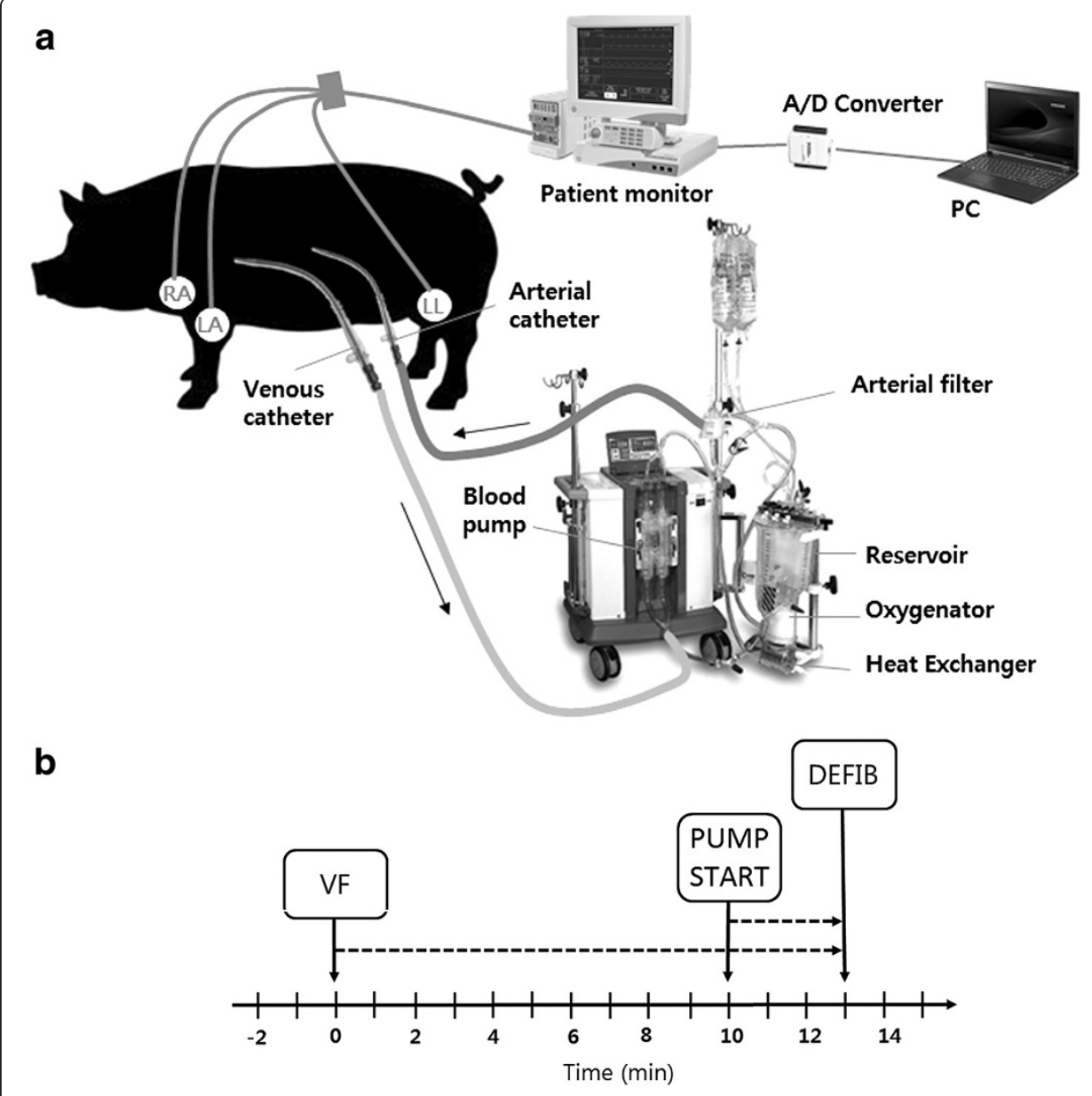

Figure 1 Schematic diagram of (a) extracorporeal blood circulation and electrocardiogram (ECG) signal acquisition and (b) experimental timeline. Blood pump was started at $10 \mathrm{~min}$ after ventricular fibrillation (VF) induction and defibrillation (DEFIB) was applied at 3 min after blood pump started. ECG waveforms were recorded for $13 \mathrm{~min}$.

sample points. The Hanning window is known to be suitable to random signal and has good frequency resolution and reduced spectral leakage.

The spectrogram at time $\tau$ and frequency $\mathrm{f}$ can be acquired by computing the squared magnitude of STFT as follows:

$$
\operatorname{spectrogram}(\tau, f)=\left|\int_{-\infty}^{\infty} x(t) g(t-\tau) e^{-j 2 \pi f t} d t\right|^{2}
$$

Median frequency (MF) indicates the frequency of the spectral mass center of the power spectrum and is calculated as follows:

$$
\operatorname{MF}(\tau)=\frac{\sum_{i=4}^{50} \mathrm{f}_{i}(\mathrm{\tau}) \times \mathrm{p}_{i}(\mathrm{\tau})}{\sum_{i=4}^{50} \mathrm{p}_{i}(\mathrm{\tau})}
$$

where $f_{i}(\tau)$ is the frequency component at time $\tau$, and $p_{i}$ is the power component at frequency $\mathrm{f}_{i}(\mathrm{\tau})[3]$. 
Dominant frequency (DF) is the peak power frequency, defined as follows:

$$
\mathrm{DF}(\tau)=\mathrm{f}_{\max (\mathrm{p})}(\mathrm{\tau})
$$

where $f_{\max (p)}(\tau)$ is the frequency with the maximum power component at time $\tau$ [25].

AMSA indicates the area of the amplitude spectrum curve at a point of time and is calculated as follows:

$$
\operatorname{AMSA}(\tau)=\sum_{i=4}^{50} \mathrm{~A}_{\mathrm{i}}(\tau) \times \mathrm{f}_{\mathrm{i}}(\tau)
$$

where $\mathrm{A}_{\mathrm{i}}(\tau)$ is the amplitude $(\mathrm{mV})$ at frequency $\mathrm{f}_{\mathrm{i}}(\tau)$ at time $\tau$, and the frequency band is between 4 and $50 \mathrm{~Hz}[6,26]$.

All calculations were performed using the numerical computing software, Matlab (MathWorks, Inc., Natick, MA, USA). The STFT results were demonstrated by spectrogram. MF, DF, and AMSA were presented as the mean and standard deviations.

\section{Results}

All procedures and signal measurements were successfully accomplished without any problems in all animals. Each defibrillation trial after a 3-min ECPR was successful.

Figure 2 shows the representative 5-sec ECG waveforms successively obtained from the same swine VF model. Figure 3 shows a representative typical spectrogram calculated by STFT during VF, which was not preprocessed by a $4-50 \mathrm{~Hz}$ band-pass filter. After VF induction, a strong power band appeared at approximately $10 \mathrm{~Hz}$ with a downward trend to $6-7 \mathrm{~Hz}$ until $2 \mathrm{~min}$. It then rebounded and peaked beyond $10 \mathrm{~Hz}$ until $4.5 \mathrm{~min}$. After $5 \mathrm{~min}$, the band decreased slightly until $10 \mathrm{~min}$. The strong frequency band disappeared immediately after the oxygenated blood was supplied. However, approximately $30 \mathrm{sec}$ later, a strong band developed again from a very low frequency region and increased remarkably above $15 \mathrm{~Hz}$ within 2 min. Simultaneously, several harmonic spectral lines were observed with a strong low frequency spectrum for 1 minute.

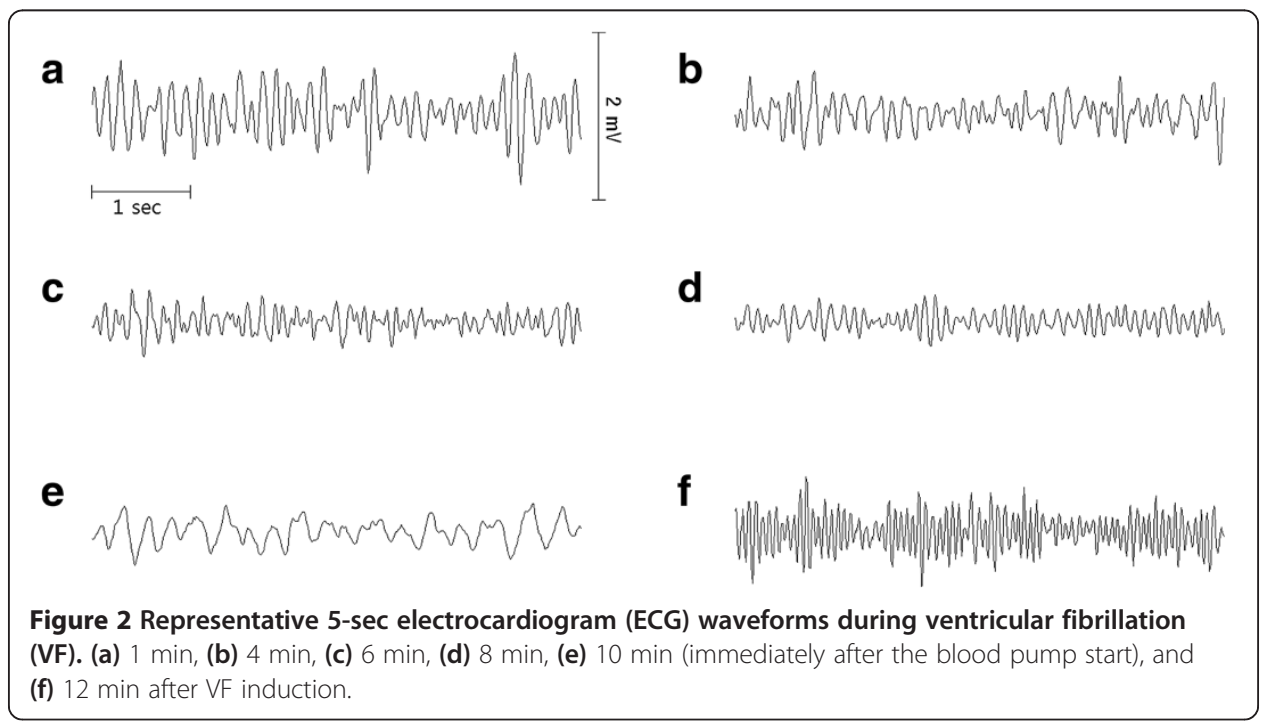




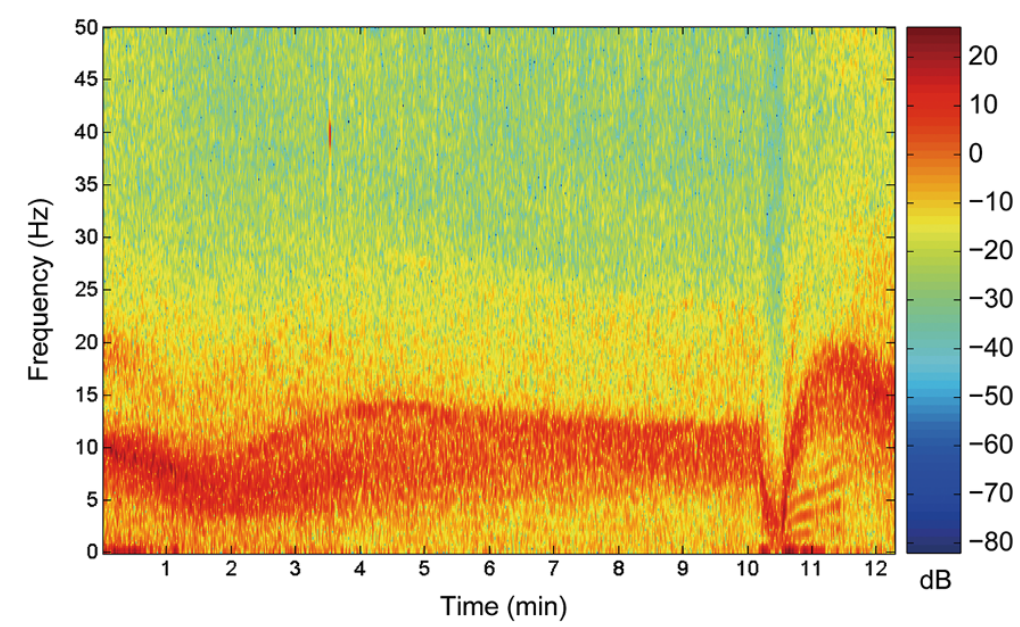

Figure 3 A spectrogram analysis from electrocardiogram (ECG) signal obtained during ventricular fibrillation (VF). The Hanning window function was used with a size of $1.7 \mathrm{sec}$ with 512 sample points. Supplying oxygenated blood started at $10 \mathrm{~min}$ after VF induction. To show the original characteristic of the ECG signal, this spectrogram is not preprocessed by a $4-50 \mathrm{~Hz}$ band-pass filter. As a result, remarkable harmonic spectral lines with a strong low frequency spectrum observed for a minute due to a mechanical artifact by a pulsatile blood perfusion after ECPR was initiated. The color bar indicates the power in $\mathrm{dB}$ with red representing high power and blue low power.

The mean MF value was $11 \mathrm{~Hz}$ at the start during VF, which decreased to $9 \mathrm{~Hz}$ until $2 \mathrm{~min}$, and then rebounded to $11 \mathrm{~Hz}$ until $4.5 \mathrm{~min}$ (Figure 4a). However, DF presented a different initial trend to that of MF (Figure 4b). DF started at $7 \mathrm{~Hz}$ and increased to $11 \mathrm{~Hz}$ within $1 \mathrm{~min}$, decreased to $9 \mathrm{~Hz}$ until $2 \mathrm{~min}$, then increased again to $12 \mathrm{~Hz}$ until 4.5 min. After the start of the oxygenated blood supply, both MF and DF increased significantly after a short slight descent and exceeded $12 \mathrm{~Hz}$ and $14 \mathrm{~Hz}$, respectively. Similarly, the mean AMSA decreased gradually until 10 min but then increased remarkably after the start of the blood pump (Figure 5).

\section{Discussion}

The ECG has been widely used to observe cardiac physiology and to predict possible heart arrest. The amplitude of the ECG waveform during VF is a very effective indicator to predict survival outcome, and it steadily decreases during VF with increasing arrest time [25]. Another study reported that VF frequency change has been applied to estimate cardiac arrest duration by analyzing the trend in frequency change [26]. Both MF and DF can increase by performing CPR, and the MF, in particular, is related to the myocardial blood flow rate [11]. Furthermore, CPR prior to defibrillation elevates MF from $8.8 \mathrm{~Hz}$ to $15.1 \mathrm{~Hz}$ and improves the outcome of the ROSC significantly [12]. In this study, we showed that the oxygenated blood supply after $10 \mathrm{~min}$ of VF elevated MF from $8 \mathrm{~Hz}$ to $12 \mathrm{~Hz}$ and DF from $9 \mathrm{~Hz}$ to $14 \mathrm{~Hz}$ in swine VF models, suggesting that ECPR during VF improved the myocardial blood flow rate and helped the recovery of cardiac function.

The three-phase time-sensitive model suggested by Weisfeldt et al. [27] is helpful to understand the successive features of cardiac arrest and to perform appropriate therapy for each phase. The three phases of the cardiac arrest model are: (1) the electrical phase, which spans approximately $4 \mathrm{~min}$ from the start of cardiac arrest, (2) the circulatory phase 


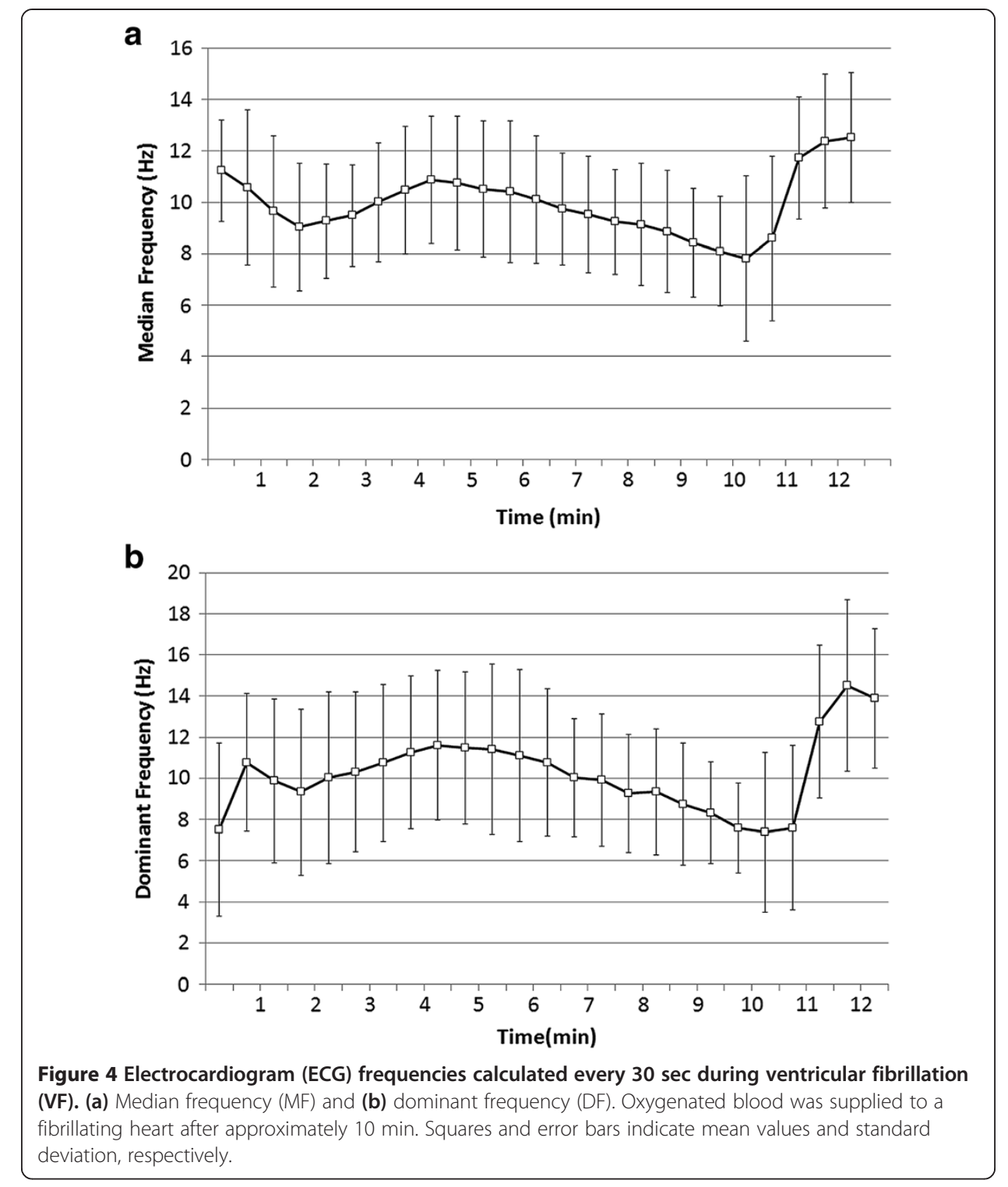

from approximately 4 to $10 \mathrm{~min}$, and (3) the metabolic phase extending beyond approximately $10 \mathrm{~min}$ after cardiac arrest. Early defibrillation is the most effective intervention during the electrical phase. However, the most lifesaving therapy during the circulatory phase is performing CPR to provide oxygen delivery followed by defibrillation. During the metabolic phase, the effectiveness of both immediate defibrillation and CPR prior to defibrillation is poor, but hypothermia is an effective method to prevent ischemic cell damage in tissues. In this study, the MF and DF variations observed during ECPR could be explained by the three-phase time-sensitive model. During the electrical phase ( $0-4 \mathrm{~min})$, both the MF and DF decreased slightly and then increased to a peak. Throughout the circulatory phase (4-10 min), both frequencies decreased gradually. After initiation of ECRP (10 min), the frequencies increased again after a short descent as the oxygenated blood was delivered to the heart and reached another peak. The descent might be due to an instantaneous delivery of the deoxygenated blood which was previously located in the aorta and the priming solution in the blood circuit. Several harmonic spectral lines with a 


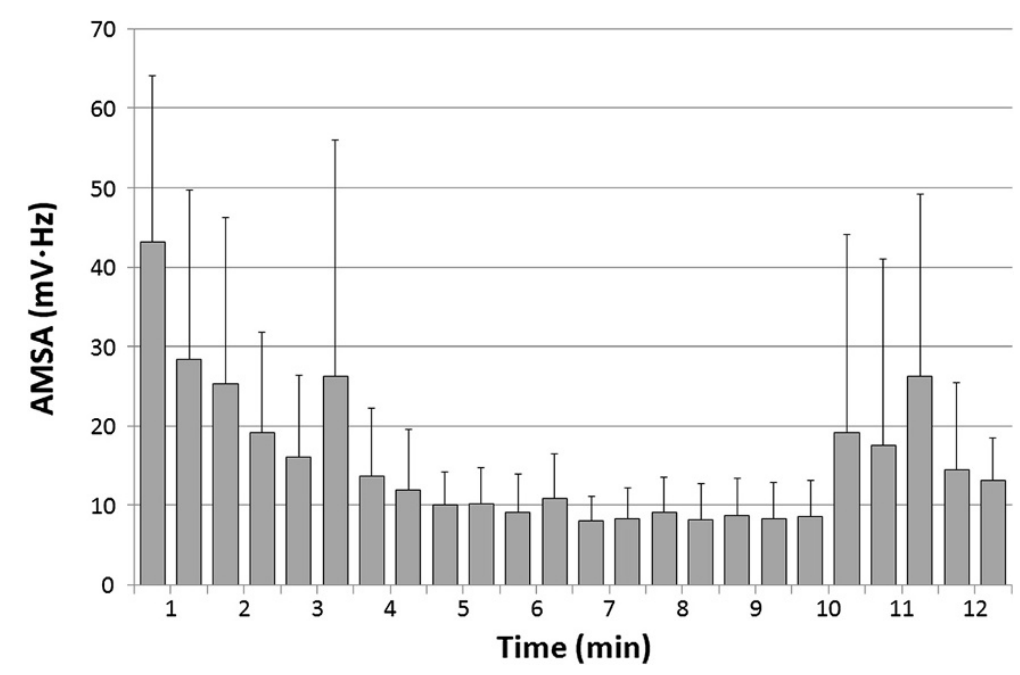

Figure 5 Mean amplitude spectrum area (AMSA, $\mathrm{mV} \cdot \mathrm{Hz}$ ) calculated every $30 \mathrm{sec}$ during ventricular fibrillation (VF). Error bars indicate the standard deviation.

strong low frequency spectrum observed for a minute after ECPR was initiated. The low frequency artifacts diminished after MF and DF reached the peaks. These spectral harmonics might be due to a mechanical artifact by ECPR perfusion.

Similarly, AMSA decreased gradually after VF induction until ECPR was started and rebounded from a bottom plateau around $8 \mathrm{mV} \cdot \mathrm{Hz}$ up to about $26 \mathrm{mV} \cdot \mathrm{Hz}$ after the blood pump started (Figure 5). The typical AMSA values for swine or human models has been known as a range between $5-30 \mathrm{mV} \cdot \mathrm{Hz}$, and the values above $13-21 \mathrm{mV} \cdot \mathrm{Hz}$ during arrest are a strong predictor of survival [28,29]. In the present study, mean AMSA increased after the oxygenated blood supply started and varied beyond $13 \mathrm{mV} \cdot \mathrm{Hz}$ until the defibrillation was performed. This increase of AMSA might make every trial of defibrillation successful.

Some limitations to this experimental study should be noted. First, we did not assess the outcome of defibrillation success or ROSC. Although all trials of defibrillation after ECPR were successful, the effectiveness of ECPR for improving ROSC is still unproven through this study. However, clinical reports comparing the effectiveness of ECPR and conventional CPR are currently being published [30,31]. Second, coronary blood flow was not simultaneously measured with the ECG during ECPR support, although the measurement method for the parameters was well known. We were afraid that the invasive measurement might distort the ECG signal during VF and ECPR. However, some studies reported a correlation between fibrillation frequency and coronary perfusion or myocardial blood flow during manual CPR in a swine model $[12,13]$.

The results we obtained in the present study imply that the simultaneous ECG frequency analysis during ECPR gives the resuscitation provider important information about the cardiac perfusion status. When a problem occurred with cannulation or extracorporeal circuit setup, the oxygenated blood would not be properly delivered to the fibrillating heart even if the extracorporeal blood pump started on time. The resuscitation provider could timely recognize an occurrence of the critical problem by monitoring the ECG frequency change after ECPR support started, and an immediate step would be taken to solve the problem. 


\section{Conclusions}

We have measured the ECG signals in a swine VF model and performed frequency analyses to observe the change in fibrillation frequency by supplying oxygenated blood to a fibrillating heart. Remarkable frequency increases in ECG due to the oxygenated blood perfusion during ECPR were observed. The ECG frequency analysis during ECPR can give the resuscitation provider important information about the cardiac perfusion status and the appropriateness of the ECPR setup as well as the prediction of defibrillation success.

\section{Competing interests}

The authors declare that they have no competing interests.

\section{Authors' contributions}

The animal experimental study was planned and performed by JCL with support by GJS. The signal acquisition and frequency analysis were performed by JCL with support by HCK. The manuscript was written by JCL, and revised by $J C L$, GJS and HCK. All authors approved the final version of the manuscript.

\section{Acknowledgements}

This work was supported by the National Research Foundation of Korea (NRF) grants funded by the Korea government (MEST) (NRF-2012R1A1A2008243). We thank Seoul National University Medical Electronics Laboratory for technical assistance and National Medical Center for providing research resource.

\section{Author details \\ ${ }^{1}$ Institute of Medical and Biological Engineering, Medical Research Center, Seoul National University, Yongon-dong 28, Jongro-gu, Seoul 110-744, Republic of Korea. ${ }^{2}$ Department of Emergency Medicine, Seoul National University College of Medicine and Seoul National University Hospital, Yongon-dong 28, Jongro-gu, Seoul 110-744, Republic of Korea. ${ }^{3}$ Department of Biomedical Engineering, Seoul National University College of Medicine and Seoul National University Hospital, Yongon-dong 28, Jongro-gu, Seoul 110-744, Republic of Korea.}

Received: 15 August 2013 Accepted: 8 November 2013

Published: 25 November 2013

\section{References}

1. Amann A, Rheinberger K, Achleitner U: Algorithms to analyze ventricular fibrillation signals. Curr Opin Crit Care 2001, 7(3):152-156.

2. Noc M, Weil MH, Tang W, Sun S, Pernat A, Bisera J: Electrocardiographic prediction of the success of cardiac resuscitation. Crit Care Med 1999, 27(4):708-714.

3. Dzwonczyk R, Brown CG, Werman HA: The median frequency of the ECG during ventricular fibrillation: its use in an algorithm for estimating the duration of cardiac arrest. IEEE Trans Biomed Eng 1990, 37(6):640-646.

4. Patwardhan A, Moghe S, Wang K, Leonelli F: Frequency modulation within electrocardiograms during ventricular fibrillation. Am J Physiol Heart Circ Physiol 2000, 279(2):H825-835.

5. Patwardhan A, Wang K, Moghe S, Leonelli F: Bispectral energies within electrocardiograms during ventricular fibrillation are correlated with defibrillation shock outcome. Ann Biomed Eng 1999, 27(2):171-179.

6. Povoas HP, Bisera J: Electrocardiographic waveform analysis for predicting the success of defibrillation. Crit Care Med 2000, 28(11 Suppl):N210-211.

7. Addison PS: Wavelet transforms and the ECG: a review. Physiol Meas 2005, 26(5):R155-199.

8. Watson JN, Addison PS, Clegg GR, Holzer M, Sterz F, Robertson CE: A novel wavelet transform based analysis reveals hidden structure in ventricular fibrillation. Resuscitation 2000, 43(2):121-127.

9. Amann A, Achleitner U, Antretter H, Bonatti JO, Krismer AC, Lindner KH, Rieder J, Wenzel V, Voelckel WG, Strohmenger HU: Analysing ventricular fibrillation ECG-signals and predicting defibrillation success during cardiopulmonary resuscitation employing N(alpha)-histograms. Resuscitation 2001, 50(1):77-85.

10. Jang SJ, Lee JS, Seong HM, Yoon YR, Hwang SO, Lee HS: Analysis of relation between coronary perfusion pressure and the extracted parameters from a ventricular fibrillation ECG signal. In Proceedings of the 26th Annual International Conference of the IEEE Engineering in Medicine and Biology Society: 1-5 September 2004. San Francisco, CA; 2004:3989-3992.

11. Strohmenger HU, Lindner KH, Keller A, Lindner IM, Pfenninger EG: Spectral analysis of ventricular fibrillation and closed-chest cardiopulmonary resuscitation. Resuscitation 1996, 33(2):155-161.

12. Berg RA, Hilwig RW, Ewy GA, Kern KB: Precountershock cardiopulmonary resuscitation improves initial response to defibrillation from prolonged ventricular fibrillation: a randomized, controlled swine study. Crit Care Med 2004, 32(6):1352-1357.

13. Berg RA, Hilwig RW, Kern KB, Ewy GA: Precountershock cardiopulmonary resuscitation improves ventricular fibrillation median frequency and myocardial readiness for successful defibrillation from prolonged ventricular fibrillation: a randomized, controlled swine study. Ann Emerg Med 2002, 40(6):563-570.

14. Kennedy JH: The role of assisted circulation in cardiac resuscitation. JAMA 1966, 197(8):615-618.

15. Biarent D, Bingham R, Eich C, Lopez-Herce J, Maconochie I, Rodriguez-Nunez A, Rajka T, Zideman D: European resuscitation council guidelines for resuscitation 2010 section 6. Paediatric life support. Resuscitation 2010, 81(10):1364-1388. 
16. Nolan JP, Soar J, Zideman DA, Biarent D, Bossaert LL, Deakin C, Koster RW, Wyllie J, Bottiger B, ERC Guidelines Writing Group: European resuscitation council guidelines for resuscitation 2010 section 1. Executive summary. Resuscitation 2010, 81(10):1219-1276.

17. Huang SC, Wu ET, Wang CC, Chen YS, Chang Cl, Chiu IS, Ko WJ, Wang SS: Eleven years of experience with extracorporeal cardiopulmonary resuscitation for paediatric patients with in-hospital cardiac arrest. Resuscitation 2012, 83(6):710-714.

18. Skarda D, Barnhart D, Scaife E, Molitor M, Meyers R, Rollins M: Extracorporeal cardiopulmonary resuscitation (EC-CPR) for hypothermic arrest in children: is meaningful survival a reasonable expectation? J Pediatr Surg 2012, 47(12):2239-2243.

19. Wolf MJ, Kanter KR, Kirshbom PM, Kogon BE, Wagoner SF: Extracorporeal cardiopulmonary resuscitation for pediatric cardiac patients. Ann Thorac Surg 2012, 94(3):874-879. discussion 879-880.

20. Chen YS, Wang CH, Chou NK, Chi NH, Yu HY: Improved outcome of extracorporeal cardiopulmonary resuscitation for out-of-hospital cardiac arrest. J Am Coll Cardiol 2013, 61(10):E1322-E1322.

21. Maekawa K, Tanno K, Hase M, Mori K, Asai Y: Extracorporeal cardiopulmonary resuscitation for patients with out-of-hospital cardiac arrest of cardiac origin: a propensity-matched study and predictor analysis. Crit Care Med 2013, 41(5):1186-1196.

22. McMullan DM: Expanding the availability of extracorporeal cardiopulmonary resuscitation. Pediatrics 2013, 131(3):e934-938.

23. Kim HK, Son HS, Fang YH, Park SY, Hwang CM, Sun K: The effects of pulsatile flow upon renal tissue perfusion during cardiopulmonary bypass: a comparative study of pulsatile and nonpulsatile flow. ASAIO J 2005, 51(1):30-36.

24. Lim CH, Son HS, Baek KJ, Lee JJ, Ahn CB, Moon KC, Khi W, Lee H, Sun K: Comparison of coronary artery blood flow and hemodynamic energy in a pulsatile pump versus a combined nonpulsatile pump and an intra-aortic balloon pump. ASAIO J 2006, 52(5):595-597.

25. Weaver WD, Cobb LA, Dennis D, Ray R, Hallstrom AP, Copass MK: Amplitude of ventricular fibrillation waveform and outcome after cardiac arrest. Ann Intern Med 1985, 102(1):53-55.

26. Brown CG, Dzwonczyk R, Werman HA, Hamlin RL: Estimating the duration of ventricular fibrillation. Ann Emerg Med 1989, 18(11):1181-1185.

27. Weisfeldt ML, Becker LB: Resuscitation after cardiac arrest: a 3-phase time-sensitive model. JAMA 2002, 288(23):3035-3038.

28. Young C, Bisera J, Gehman S, Snyder D, Tang W, Weil MH: Amplitude spectrum area: measuring the probability of successful defibrillation as applied to human data. Crit Care Med 2004, 32(9 Suppl):S356-358.

29. Povoas HP, Weil MH, Tang W, Bisera J, Klouche K, Barbatsis A: Predicting the success of defibrillation by electrocardiographic analysis. Resuscitation 2002, 53(1):77-82.

30. Chen YS, Lin JW, Yu HY, Ko WJ, Jerng JS, Chang WT, Chen WJ, Huang SC, Chi NH, Wang CH, et al: Cardiopulmonary resuscitation with assisted extracorporeal life-support versus conventional cardiopulmonary resuscitation in adults with in-hospital cardiac arrest: an observational study and propensity analysis. Lancet 2008, 372(9638):554-561.

31. Lin JW, Wang MJ, Yu HY, Wang CH, Chang WT, Jerng JS, Huang SC, Chou NK, Chi NH, Ko WJ, et al: Comparing the survival between extracorporeal rescue and conventional resuscitation in adult in-hospital cardiac arrests: propensity analysis of three-year data. Resuscitation 2010, 81(7):796-803.

doi:10.1186/1475-925X-12-123

Cite this article as: Lee et al.: Electrocardiogram frequency change by extracorporeal blood perfusion in a swine ventricular fibrillation model. BioMedical Engineering OnLine 2013 12:123.

\section{Submit your next manuscript to BioMed Central and take full advantage of:}

- Convenient online submission

- Thorough peer review

- No space constraints or color figure charges

- Immediate publication on acceptance

- Inclusion in PubMed, CAS, Scopus and Google Scholar

- Research which is freely available for redistribution

Submit your manuscript at www.biomedcentral.com/submit 